\title{
The role of trans-obturator vaginal tape (TVT-O) in the management of female stress urinary incontinence: 2 years follow up, Minia University Experience
}

Original

Article

\author{
Ahmed M. Abdel ghany \\ Department of Obstetrics and Gynecology, Faculty of Medicine, Minia University, Minia, \\ Egypt
}

\begin{abstract}
Objective: The aim of this study was to evaluate the effectiveness and safety of a new minimally invasive surgical procedure, trans-obturator vaginal tape (TVT-O), in the treatment of female stress urinary incontinence and following-up these cases for 24 months regarding effectiveness, safety and possibility of complications.

Type of the Study: with a 24 -months follow-up.

Setting: Department of Obstetrics and Gynecology, Faculty of Medicine, Minia University, Minia, Egypt.

Patients: Thirty women with genuine stress urinary incontinence (SUI) demonstrated by history, clinical examination and urodynamic study.

Methods: Thirty patients diagnosed with SUI underwent trans-obturator sling (inside-out technique) (TVT-O Gynecare ${ }^{\circledR}$, Johnsonand Johnson, USA.).

Outcome Measures: The patients were followed up for 24 - months regarding subjective and objective cure rates.

Results: The mean operative time (min.) was 19.67 ( \pm 8.06$)$. The mean intraoperative blood loss (ml) was $80 \pm 30.52$. There were no cases complicated with intraoperative bleeding (mild or severe), bladder, urethral, vascular injuries and anesthetic complications. Subjective and objective cure rates of these patients were $(95 \%)$.

Conclusion: The results of this study concluded that management of genuine stress urinary incontinence by trans-obturator vaginal tape (TVT-O) is an easy and safe method with low complications and high success rate.
\end{abstract}

Key Words: Stress urinary incontinence - Transobturator vaginal tape.

Received: 5 October 2018, Accepted: 21 October 2018

Corresponding Author: Ahmed M. Abdel ghany MSc, Department of Obstetrics and Gynecology, Faculty of Medicine, Minia University, Minia, Egypt, E-mail: ahmedabdelghany28@yahoo.com

ISSN: 2090-7265, November 2018, Vol.8, No. 4

\section{INTRODUCTION}

Urinary incontinence is a significant health problem in the developed and the developing countries. Population studies have shown that about $10-35 \%$ of all women had urinary incontinence ${ }^{[1]}$. Stress urinary incontinence (SUI) is the most common type of incontinence. A lot of different techniques are used for the treatment of SUI ; slings are the most effective and durable form of treatment ${ }^{[2]}$. Various tissues and synthetic materials are used for that purpose. The new synthetic materials, replacing the torn fascia, are the basis of the recent development of a multitude of surgical techniques of SUI and other pelvic floor lesions. The tension-free vaginal tape (TVT) procedure has revolutionized the surgery of female SUI, and it is now considered by many surgeons to be the goldstandard surgery for female SUI with excellent longterm efficacy ${ }^{[3]}$. The TVT procedure, which uses a retropubic route, has been associated with a number of complications resulting from penetrations of the surgical device into pelvic vessels, nerves and organs ${ }^{[4]}$. The trans-obturator vaginal tape (TVT-O) approach was developed for female SUI with the aim of avoiding the risk of urethra and bladder injuries with minimal vaginal dissection within a short period of time ${ }^{[5]}$. The procedure is now the most popular technique in many worldwide centers with good results.

\section{PATIENTS AND METHODS}

This study was carried out at the Department of Obstetrics and Gynecology Faculty of Medicine, El-Minia University, from September 2007 to February 2010.

The study included thirty patients diagnosed to have genuine stress urinary incontinence (SUI) demonstrated by history, clinical examination and urodynamic study. 


\section{Ethical issue:}

Following ethical guidelines of the research, an approval was taken from the Department Ethical Committee before the start of the research. Also, written informed consent was taken from each patient.The objectives of the study were explained for each patient, as well as the details of the used procedure.

\section{Sample size calculation:}

The study consisted of 30 patients, this sample size was calculated by a specific program called EPIINFO. For using this method to calculate the sample, the following data are needed:

1. Prevalence of the female urinary stress incontinence from previous Researches.

2. Total number of population under the study.

The sample size required can be calculated according to the following formula.

\section{Formula:}

$$
\begin{gathered}
n=t^{2} \times p(1-p) \\
m^{2}
\end{gathered}
$$

\section{Description:}

$\mathrm{n}=$ required sample size

$\mathrm{t}=$ confidence level at $95 \%($ standard value of 1.96$)$

$\mathrm{p}=$ estimated prevalence of the project area

$\mathrm{m}=$ margin of error at $5 \%$ (standard value of 0.05$)$

\section{PATIENTS ELIGIBLE CRITERIA:}

\section{Inclusion Criteria:}

- Genuine stress urinary incontinence by history, examination and urodynamic studies.

- No contraindications for surgery.

- Any age was included in the study; postmenopausal patients were given HRT to exclude postmenopausal atrophy. HRT was taken in the form of tibolone tablets for 3 months before included in the study.

\section{Exclusion Criteria:}

- Patients with urge or mixed type of incontinence

- Pregnancy.

- $\quad<3$ months post-partum

- Systemic disease known to affect bladder function.

- Current chemotherapy or radiation therapy

- Urethral diverticulum, augmentation cystoplasty, or artificial sphincter

- History of recent severe pelvic infections documented by clinical picture and investigations.

- Known extensive abdominopelvic adhesions

- Detrusor instability.

- Lower urinary tract anomaly.

- Urogenital prolapse of second degree or more.

- Active malignancy.

- Anticoagulant therapy and Haemorrhagic blood diseases.

- Immobile patient.

- $\quad$ Other gynaecologic pathologies (e.g., fibroids, ovarian cysts).

\section{Diagnosis:}

For all patients, physical examination with cough stress test, urine culture and sensitivity and preoperative urodynamics examination were performed. The cough stress test is done with full bladder ( $300 \mathrm{ml}$ measured by ultrasound). The patient is asked to cough and bear down; urine is usually lost in small spurts with each cough. Delayed urine loss, particularly large volume loss or complete bladder emptying occurring after coughing, is suggestive of unstable bladder activity. If the stress incontinence is not demonstrated in a standard lithotomy position, the test should be repeated in the standing position with the patient's feet comfortably separated at shoulder width. In cases of associated cystocele and/or rectocele, the test is done before and after insertion of a vaginal pack $^{[6]}$. Cases with a neurogenic bladder or with evident urge incontinence were excluded. If there 
was a defect in pelvic floor support, it was corrected with an appropriate technique. All subjects received intravenous prophylactic antibiotic therapy at the beginning of surgery.

\section{Urodynamic Study:}

- All patients underwent urodynamic evaluation preoperatively. The system used in urodynamic evaluation was Delphis, KT Labories Company, Germany.

- The urodynamic studies were done by $\mathrm{Dr} /$ Mohammad Salah El- Badry, Lecture of Urology, El- Minia University.

- The following studies were done:

- Uroflowmetry

- Cystometry

- ALPP (abdominal leak point pressure)

- Pressure-flow study

\section{Operative procedure of trans-obturator vaginal tape operation:}

The tape is polypropylene tape called TVT-O Gyncare, Johnson and Johnson, USA. The surgical technique was the same as described by de Leval in $2003^{[7]}$. There are ten key procedural steps. The procedures were performed under spinal anesthesia. Place patient in the dorsal lithotomy position with hips flexed. Mark the exit points of the plastic tubes by tracing a horizontal line at the level of the urethral meatus and a second line parallel and $2 \mathrm{~cm}$ above the first line. The exit points are marked on the second line, $2 \mathrm{~cm}$ lateral to the folds of the thigh. Make a 5-mm incision at each exit point. Make a 1-cm midline vaginal incision starting $1 \mathrm{~cm}$ proximal to the urethral meatus. Bluntly dissect to the obturator membrane and perforate it using curved scissors. The pathway of the lateral dissection should be orientated at a $45^{\circ}$ angle from the midline sagittal plane. Insert the winged guide and helical passer. Push the device inward, traversing and slightly passing the obturator membrane. Rotate the helical passer while moving into midline. Facilitate passage of the instrument through skin incision. Grasp the tip of the plastic tube to stabilize then retract helical passer by reverse rotation. Pull plastic tube and tape completely through skin. Repeat the technique on the patient's other side ensuring that the tape lies flat under urethra. Adjust the tape according to your preference, remove plastic sheath, and close incisions.

\section{Post-operative evaluation:}

- Prophylactic antibiotics are needed for 2 doses; only one dose intra-operative and another dose during hospital stay.

- Collection of data regarding operative time, type of anesthesia, post- operative analgesia and duration of hospital stay were done.

- Intra-operative and post-operative complications were reported if present.

Postoperative complications were recorded and including urinary retention, voiding difficulty, de novo urgency, recurrent urinary tract infection and dyspareunia.

\section{Follow up and outcome measures:}

The outcome score of surgical treatment was estimated as follows: the subjective cure $=$ no urine loss during stress, objective cure $=$ no leakage of urine with cough at the bladder capacity of $300 \mathrm{ml}$, and improvement=significantly fewer leakage episodes during stress than before surgery. All other patients were classified as failures, even if a clear improvement from the preoperative situation has occurred.

\section{Statistical analysis:}

Comparisons between preoperative and postoperative values were performed with the paired Student's t test. Statistical tests $p<0.05$ were considered statistically significant. Analyses were performed with the Stat View ${ }^{\circledR}$ statistical software package.

\section{RESULTS}

Thirty patients were enrolled in this study. Followup and complete data were available for all these patients. Other patients' characteristics are shown in Table (1). In our study, the mean ( \pm SR) age for these patients was $35.4( \pm 7.1)$ year. In our work, the operative time in these patients ranged from 15 to 22 minutes, from the beginning of the technique. The mean operative time ( \pm SR) for these patients was $19.67( \pm 8.06)$ minutes.

In the present study, no case, in these patients, was complicated by intraoperative bleeding either mild or severe bleeding; so, blood transfusion in these patients was not required by any case. In these patients, the mean amount of blood loss $( \pm$ SR) was $80.3 \pm(30.52)$ C.C. ranged from 50110-ml. 
Table 1: Patients characteristics in the study

\begin{tabular}{lc}
\hline \multicolumn{1}{c}{ Data } & TVT-O $(\mathrm{N}=30)$ \\
\hline Age ( mean $\pm \mathrm{SD})$ (years) & $35.4 \pm 7.1$ \\
Parity -mean $\pm \mathrm{SD}$ & $6.9 \pm 2.2$ \\
Body mass index -Mean $\pm \mathrm{SD}$ & $27.1 \pm 4.3$ \\
$\begin{array}{l}\text { Morbid obesity (BMI } \geq 35) \\
\text { (number/ total number) }\end{array}$ & $1 / 20(5 \%)$ \\
& $3(15 \%)$ \\
\hline
\end{tabular}

Table 2: Previous gynecological surgery of the patients in the study

\begin{tabular}{cc}
\hline Data & TVT-O (N=30) \\
\hline Previous surgery for urinary incontinence & $* 2(10 \%)$ \\
Previous surgery for prolapse & $* 3(15 \%)$ \\
\hline
\end{tabular}

Table 3: Intraoperative data of the patients

\begin{tabular}{lc}
\hline \multicolumn{1}{c}{ Data } & TVT-O $(\mathrm{N}=30)$ \\
\hline Type of anesthesia & $30(100 \%)$ \\
$\bullet \quad$ regional anesthesia & $0(0 \%)$ \\
general anesthesia & $19.67 \pm 8.06$ \\
- mean $\pm \mathrm{SD}$ & \\
Intraoperative blood loss(ml) & $80 \pm 30.52$ \\
- mean $\pm \mathrm{SD}$ & \\
Length of hospital stay(days) & $1.46 \pm 0.9$ \\
Mean $\pm \mathrm{SD}$ & \\
\hline
\end{tabular}

Regarding intra-operative complications of each technique, no case, in these patients, was complicated by intraoperative bleeding, bladder injury, urethral injury, vascular injury, intestinal injury and anesthetic complications.

Table 4: Intraoperative complications of the patients

\begin{tabular}{lc}
\hline \multicolumn{1}{c}{ Data } & TVT-O $(\mathrm{N}=30)$ \\
\hline Intraoperative bleeding & \\
- Mild bleeding(more than $500 \mathrm{ml})$ & $0(0 \%)$ \\
-severe bleeding (more than $1000 \mathrm{ml})$ & $0(0 \%)$ \\
Bladder injury & $0(0 \%)$ \\
Urethral injury & $0(0 \%)$ \\
Vascular injury & $0(0 \%)$ \\
\hline
\end{tabular}

Table 5: Subjective and objective success rates of these patients at 2 years postoperative

\begin{tabular}{|c|c|c|}
\hline & Data & TVT-O $(\mathrm{N}=30)$ \\
\hline \multicolumn{3}{|c|}{ * Subjective success rate } \\
\hline- & Cured & $29(95 \%)$ \\
\hline- & Improved & $0(0 \%)$ \\
\hline- & Failed & $1(5 \%)$ \\
\hline \multicolumn{3}{|c|}{ Objective success rate } \\
\hline- & Cured & $29(95 \%)$ \\
\hline- & Improved & $0(0 \%)$ \\
\hline- & Failed & $1(5 \%)$ \\
\hline
\end{tabular}

\section{DISCUSSION}

During early cases in this study and because of the previous experience with the fascial slings ${ }^{[10]}$, it was easy to shift to trans-obturator sling without considerable difficulty.

In the present study, there was no statistically significant difference regarding the mean $\pm \mathrm{SD}$ age in these patients $(35.4 \pm 3.1)$. These results were different from the results of Taweel and Rabah 2010 ${ }^{[11]}$ who reported that the mean age was $50 \pm 9$ (range from 37 to 72 years) in the TVT-O group. Also, these results were different from the results of de Leval 2003[7] who evaluate the safety and effectiveness of TVT-O in which the mean age of 107 patients was 62 years (range from 32 years to 82 years, $\mathrm{SD} \pm 10.7$ years).

In the present study, no cases, in these patients, were complicated by intraoperative bleeding either mild or severe bleeding; so, blood transfusion, in these patients, was not required. The mean amount of blood loss $( \pm$ SR) was $80.3 \pm(30.52)$ C.C. (ranging from 50 to $110 \mathrm{ml}$ ). Similarly, Dobson and Co-workers in $2007^{[12]}$ have reported bleeding less than $100 \mathrm{ml}$ in $94 \%$ of their patients using the TVT-O technique. However, Minalgia et $\mathrm{ll}^{[13]}$ reported bladder perforation in 3 of 61 patients during TVT-O placement and recommended the routine use of intraoperative cystoscopy in this procedure. It should be noted that all the three patients with bladder perforation had undergone previous pelvic surgery and these complications occurred mainly in conjunction with a large C-shaped TVT-O needle.

Regarding intra-operative complications of each technique, no case in group I complicated by intraoperative bleeding, bladder injury, urethral injury, vascular injury, intestinal injury and anesthetic complications was reported. In comparing different techniques of midurethral slings, Silva reported that the short-term efficacy of TVT-O midurethral slings 
is comparable with the retropubic slings. In addition, the risk of bladder injury may be the least with insideout approach $^{[14]}$. In another study of 390 women who underwent TVT-O (either outside-in or inside-out) for the treatment of SUI, four lower urinary tract injuries $(1 \%)$, two urethral injuries $(0.5 \%)$, and two bladder injuries $(0.5 \%)$ occurred were reported.

In the present study, the subjective and objective cure rate in these patients was $95 \%$.

These results were in agreement with the results of Taweel and Rabah $2010^{[11]}$ who demonstrated $92 \%$ cure rate after 1 month and $85 \%$ after 2 months in TVT-O group.

These results were in agreement with the results of Waltregny et al $2005^{[17]}$ who found that the subjective cure rate was $95 \%(97 / 102)$ at 8 weeks as well as $94.6 \%$ and $95.4 \%$ at 6 and 12 months, respectively.

In 2008, Nilsson et al. ${ }^{[20]}$ who introduced the TVT-O technique in 1996, found that at 11 years after operation: $90 \%$ of the women were still objectively cured at the last follow-up and no late-onset adverse effects of the operation were found. Similar data were reported by Liapis et al. 2008 ${ }^{[21]}$ at 5- and 7-year follow-up.

\section{CONCLUSION}

This study revealed that trans-obturator vaginal tape (TVT-O) is an easy and safe method for the treatment of female SUI. Also, the success rate is high with few complications.

\section{REFERENCES}

1. Milsom I, Ekelund P, Molander U, Arvidsson L, Areskoug B (1993) The influence of age, parity, oral contraception, hysterectomy and menopause on the prevalence of urinary incontinence in women. J Urol 149:1459-1462

2. Blaivas JG, Jacobs BZ (1991) Pubovaginal fascial sling for the treatment of complicated stress urinary incontinence. J Urol 145:1214-1218

3. Nilsson CG, Kuuva N, Falconer C, Rezapour M, Ulmsten U (2001) Long-term results of the tensionfree vaginal tape (TVT) procedure for surgical treatment of female stress urinary incontinence. Int Urogynecol J Pelvic Floor Dysfunct 12(Suppl 2):S5-S8

4. Boustead GB (2002) The tension-free vaginal tape for treating female stress urinary incontinence. BJU Int 89:687-693
5. DeLorme E (2001) Transobturator urethral suspension: mini-invasive procedure in the treatment of stress urinary incontinence in women. Prog Urol 11:1306-1313

6. Ghoniem GM, Walters F, Lewis V (1994) The value of the vaginal pack test in largecystoceles. $\mathrm{J}$ Urol 152:931-934

7. de Leval J (2003) Novel surgical technique for the treatment of female stress urinary incontinence: transobturator vaginal tape inside-out. Eur Urol 44:724-730

8. Burch JC. Urethrovaginal fixation to Cooper's ligament for correction of stress incontinence, cystocele, and prolapse. Am J Obstet Gynecol 1961. 81:281-290

9. Waltregny D, Reul O, Mathantu B, Gaspar Y, Bonnet P, de Leval J (2006) Inside out transobturator vaginal tape for the treatment of female stress urinary incontinence: interim results of a prospective study after a 1-year minimum followup. J Urol 175:2191-2195

10. Ghoniem GM, Elgamasy AN, Elsergany R, Kapoor DS (2002) Grades of intrinsic sphincteric deficiency (ISD) associated with female stress urinary incontinence. Int Urogynecol J Pelvic Floor Dysfunct 13:99-105

11. Taweel WA, Rabah DM. Transobturator tape for female stress incontinence: follow-up after 24 months. Can Urol Assoc J. 2010 Feb;4(1):336-.

12. Dobson A, Robert M, Swaby. C, Murphy M, Birch C, Mainprize T. Ross S. Trans $\neg$ obturator surgery for stress urinary incontinence: 1-year followup of a cohort of 52 women. Int Urologynecol J Pelvic Floor Dysfimct,2007; 18( 1 ):2732-.

13. Minaglia S, Ozel B, Klutke C, Ballard C, Klutke J (2004) Bladder injury during transobturator sling. Urology 64:376-377

14. Silva WA (2007) Treatment of stress urinary incontinence - midurethral slings: top-down, bottom-up, "outside-in," or "inside-out". Clin Obstet Gynecol 50:362-375

15. Abdel-Fattah M, Ramsay I, Pringle S (2006) Lower urinary tract injuries after transobturator tape insertion by different routes: a large retrospective study. BJOG 113:1377-1381 
16. Hinoul P, Vanormelingen L, Roovers JP, de Jonge E, Smajda S (2007) Anatomical variability in the trajectory of the inside-out transobturator vaginal tape technique (TVT-O). Int Urogynecol J Pelvic Floor Dysfunct 18:1201-1206

17. Waltregny D, Bonnet $\mathrm{P}$, Reul $\mathrm{O}$, de Leval J (2005) Transobturator vaginal tape inside out for the surgical treatment of female stress urinary incontinence: anatomical considerations. J Urol 173:1223-1228

18. Almeida M, Colaço J, Santos Pereira H, et al . Burch colposuspension. Acta Med Port. 2004 JanFeb;17(1):159-. Epub 2004 Feb 27.

19. Thaweekul Y, Bunyavejchevin S, Wisawasukmongchol W, et al : Long term results of anterior colporrhaphy with Kelly plication for the treatment of stress urinary incontinence. J Med Assoc Thai. 2004 Apr; 87(4) : 357 - 60.
20. Nilsson CG, Palva K, Rezapour M, et al : Eleven years prospective follow-up of the tension-free vaginal tape procedure for treatment of stress urinary incontinence. Int Urogynecol J Pelvic Floor Dysfunct 2008, 19:1043-1047.

21. Liapis A, Bakas P, Creatsas G, Long-term efficacy of tension-free vaginal tape in the management of stress urinary incontinence in women: efficacy at 5- and 7-year follow-up. Int Urogynecol J Pelvic Floor Dysfunct 2008, 19:1509-1512. 